\title{
QUANTIFYING CORN NITROGEN DEFICIENCY AND APPLICATION RATE WITH ACTIVE CANOPY SENSORS
}

\author{
J.E. Sawyer and D.W. Barker \\ Iowa State University, Ames, IA
}

\section{Introduction}

Precision agriculture technologies are an integral part of many crop production operations. However, implementation for $\mathrm{N}$ application has lagged, primarily due to lack of a viable system for variable $\mathrm{N}$ rate decisions. Active canopy sensors have been developed as a tool to determine plant $\mathrm{N}$ stress deficiency and provide an on-the-go decision for implementing variable rate. Two general approaches could be implemented. One is to plan on conducting canopy sensing each year, with a reduced $\mathrm{N}$ rate applied preplant, at planting, or early sidedress and then sensing conducted at mid-vegetative growth to determine additional application need. A second is to conduct sensing only if conditions result in $\mathrm{N}$ loss from the primary $\mathrm{N}$ application, or other factors change expected crop requirements. Both approaches could address variable $\mathrm{N}$ fertilization and seasonal circumstances.

Canopy reflectance measurement with active sensors is a relatively new method of remote sensing. It is similar to that of natural light reflectance with passive sensing technologies. However, active canopy sensors utilize their own light source and measure light reflectance in real-time at the canopy level. Initial research with the GreenSeeker (NTech Industries, Ukiah, CA) active canopy sensor in Oklahoma documented that active sensors are a viable method to improve $\mathrm{N}$ use efficiency in winter wheat (Raun et al., 2002), and when compared to uniform $\mathrm{N}$ rate application based on traditional yield goal, $\mathrm{N}$ use efficiency was improved $15 \%$. In corn, research with active sensors has investigated issues such as growth stage for sensing, need for normalization of sensor readings to non-limiting $\mathrm{N}$ field areas, and calibration of sensor indices to $\mathrm{N}$ fertilization requirements (Teal et al., 2006; Zillmann et al., 2006; Dellinger et al., 2008; Schmidt et al., 2009). Also, use of active sensors to direct variable rate $\mathrm{N}$ must include an understanding of situations where other factors are limiting growth, such as poor stand, excess water, or other nutrient deficiency.

Many canopy indices can be calculated from the visible (VIS) and near-infrared (NIR) reflectance variables collected with active sensors. Some indices emphasize specific plant canopy characteristics such as leaf area index, leaf chlorophyll, whole plant biomass, plant density, canopy temperature, and canopy moisture. These indices were originally developed from passive remote sensing systems, but are now being used to assess plant growth with active sensors near the canopy level. An example is normalized difference vegetative index (NDVI), with evaluation and $\mathrm{N}$ rate prediction models developed in corn (Sripada et al., 2008). Other indices have been developed that emphasize canopy $\mathrm{N}$ status. An example is the chlorophyll index (CHL) developed by Solari et al. (2008), with recent development of an algorithm for corn N (Solari et al., 2010).

An important consideration is the crop stage being sensed. For corn, this is still a subject of 
research. It appears that the mid-vegetative growth stage may allow for adequate expression of $\mathrm{N}$ stress, if it is to occur, and if $\mathrm{N}$ deficiency is found corn response to applied $\mathrm{N}$. In addition, each active canopy sensor and associated index may need a specific calibration to the degree of $\mathrm{N}$ deficiency stress and relation to optimal $\mathrm{N}$. The objectives of this research were to assess $\mathrm{N}$ deficiency stress levels at the V10 - V12 corn growth stages with active canopy sensors, calibrate active sensors and associated canopy indices, and develop $\mathrm{N}$ rate algorithms that can be used to determine variable rate $\mathrm{N}$ fertilization.

\section{Materials and Methods}

\section{Nitrogen Trials}

This study utilized multiple $\mathrm{N}$ rate trials conducted in corn from 2006 - 2008 (62 site-years) at seven Iowa State University Research and Demonstration Farms representing predominant Iowa soils with varying levels of $\mathrm{N}$ responsiveness. The trials included corn following soybean and continuous corn, and five to seven $\mathrm{N}$ rates in increments from 0 to $240 \mathrm{lb} \mathrm{N} /$ acre. Fertilizer $\mathrm{N}$ for all site-years was applied in spring prior to planting as ammonium nitrate broadcast on the soil surface, urea broadcast and incorporated, or urea ammonium nitrate solution surface applied and incorporated. The tillage system for all trials was chisel plow after grain harvest in fall, and field cultivation prior to corn planting in spring. Plot sizes were 6 or 8 rows with 30 -inch spacing by 50 or $65 \mathrm{ft}$ in length.

\section{Active Canopy Sensor Measurements}

The active sensors evaluated were the Crop Circle ACS-210 (CC-210) (Holland Scientific, Lincoln, NE), GreenSeeker "Red" 505 (GS-505), and GreenSeeker "Green” 506 (GS-506) (NTech Industries, Ukiah, CA). The GS-505 was used in this research only in 2007. The GS-506 sensor has not been sold in the marketplace. The CC-210 uses a single light emitting diode that rapidly pulses light at the VIS $590 \mathrm{~nm}$ and NIR $880 \mathrm{~nm}$ wavelengths. Reflected light from the canopy is captured by two silicon photodiodes on the sensor of varying spectral ranges (400 $680 \mathrm{~nm}$ and $800-1100 \mathrm{~nm}$ ). For this sensor, the VIS and NIR reflectance variable readings were captured and averaged across each plot. The GS-505 emits light at the VIS $656 \mathrm{~nm}$ ("red") and NIR $774 \mathrm{~nm}$ wavelengths. The GS-506 emits light at the VIS $560 \mathrm{~nm}$ ("green") and NIR $774 \mathrm{~nm}$ wavelengths. Only canopy indices directly provided by the GS-506 and GS-505 sensors, NDVI and inverse simple ratio index (SRI), were captured from those sensors.

Each individual sensor unit was mounted on a mast and carried by hand through the middle of each $\mathrm{N}$ rate plot at a constant speed $(4.3 \mathrm{ft} / \mathrm{sec})$ and distance above the canopy (24 - 36 inches) while collecting reflectance data. The active sensors were positioned perpendicular to the row in the nadir position $\left(0^{\circ}\right.$ angle) between the middle two corn rows. Sensing was conducted in June and July when the corn growth stage across $\mathrm{N}$ fertilizer rates averaged approximately V12 (ranging from V9 - V14).

\section{Calculations and Statistics}

Multiple indices can be calculated from the measured plant canopy reflectance data provided by the sensors. Indices evaluated in this research, and the calculation equations, are listed in (Table 1). The VIS and NIR reflectance data were not captured from the GreenSeeker sensors, so only a limited number of canopy indices were calculated for those sensors (Table 1). Relative sensor 
indices for each site-year $\mathrm{N}$ rate were calculated using the mean observed or calculated sensor index divided by the mean sensor index from the highest $\mathrm{N}$ rate within each trial site-year. Relative indices are indicated with a prefix " $\mathrm{r}$ ".

Corn grain yield response to applied $\mathrm{N}$ fertilizer was calculated for each site-year to determine if $\mathrm{N}$ rate or mean $\mathrm{N}$ rate contrasted to zero $\mathrm{N}$ was significantly different, that is, was the trial site $\mathrm{N}$ responsive. If responsive, then $\mathrm{N}$ rate was fit to regression models. The fitted regression model for each trial site was used to determine the economic optimum $\mathrm{N}$ rate (EONR) using a ratio of fertilizer cost $(\$ 0.40 / \mathrm{lb} \mathrm{N})$ and corn grain price $(\$ 4.00 /$ bu grain). The difference in applied $\mathrm{N}$ rate from the EONR (dEONR) was calculated as the EONR minus applied $\mathrm{N}$ rates within each siteyear.

The relationship between canopy indices and dEONR was determined across all site-years for each canopy sensor-index combination by fitting a quadratic-plateau regression model. The adjusted coefficient of determination $\left(\operatorname{adj} R^{2}\right)$ was used as a goodness of fit statistic to determine the best regression model. This model is the calibration of the canopy sensor index to $\mathrm{N}$ rate requirement (sensor predicted $\mathrm{N}$ rate for dEONR less than zero $\mathrm{lb} \mathrm{N} /$ acre). Without conversion of sensor indices to a relative value, no index provided a good relationship to dEONR (data not shown). Also, only relative canopy indices with high $\operatorname{adj}^{2}$ are provided; others with poor model relationships are not given in this report. Regression models were also compared to statistical model confidence limits to determine the variability in sensor predicted $\mathrm{N}$ rate with different relative canopy indices.

Quadratic-plateau models of relative canopy index values related to dEONR provide the active canopy sensing index calibration. The quadratic solution of these models was used to provide the prescribed $\mathrm{N}$ application rate algorithms. That solution is based on the quadratic equation form $\left(\mathrm{y}=\mathrm{c}+\mathrm{bx}+\mathrm{ax}^{2}\right.$; where $\mathrm{y}$ is the relative sensor index value and $\mathrm{x}$ is the $\mathrm{N}$ rate), and in $\mathrm{a}$ spreadsheet format for these equations is $-\left(\left(-b+\left(b^{\wedge} 2-4^{*} a^{*}(c-y)\right)^{\wedge} 0.5\right) /(2 * a)\right)$. Substituting the coefficients from the calibration model equation and a specific relative canopy sensor index value provides the prescribed $\mathrm{N}$ application rate.

\section{Results and Discussion}

\section{Crop, Plant Canopy, and Sensing Observations}

Sensing multiple $\mathrm{N}$ fertilizer rates across years of corn response, crop rotations, hybrids, soils, climatic environments, and fertilization practices resulted in a wide variety of plant canopies, including color and height, and provided for a robust evaluation of canopy sensing. Having diverse cropping conditions for active sensor algorithm development is important and should reflect future potential corn production environments and plant canopies.

Timing of $\mathrm{N}$ stress sensing with active canopy sensors in this study and in other recent work has focused around the V10 - V12 growth stages in corn (Solari et al., 2008). This timing may provide the best balance for attempting to accurately estimate corn $\mathrm{N}$ stress, provide adequate fertilizer $\mathrm{N}$ to growing corn plants when it is most needed, and limit severity of lost yield potential due to $\mathrm{N}$ stress. Sensor based in-season $\mathrm{N}$ application may be more time consuming compared to pre-plant $\mathrm{N}$ application, with concerns about completing applications in a timely 
manner. During this study, corn growth rate and stage development suggests that if active sensors are used to apply $\mathrm{N}$ in-season, the application window that exists in Iowa is approximately 14 days in late June to early July.

Some corn canopy conditions that negatively affected sensing readings and that can exist in production fields were also observed. These included the presence of visible corn tassels, reduced plant population, lodging due to wind damage, and leaf curling due to moisture/heat stress. Active canopy sensing to adjust $\mathrm{N}$ rates in-season should be avoided under these conditions.

\section{Active Canopy Sensor Indices Relationship to Nitrogen Rate}

As found previously with the SPAD meter, use of relative canopy index values (relative to non-N limited rate) reduced variation and greatly improved the model fit between the canopy indices and dEONR (data not shown). Therefore, relative indices were used for calibration and algorithm development instead of direct index readings. This means that for implementation of active canopy sensing in production fields there needs to be areas or strips that are known non-N limiting so relative values can be calculated.

All three active sensors discerned corn $\mathrm{N}$ deficiency stress. Not all indices, however, were equally well calibrated to $\mathrm{N}$ deficiency (Table 2; data not shown for all indices). This also varied somewhat with different sensors. For instance, the rNDVI had a better calibration fit from the CC-210 than the GS-506. In general, the non-linear (rNLI), modified normalized difference vegetative index (rMNDVI), re-normalized difference vegetative index (rRDVI), and rNIR relative canopy indices were not well calibrated. Some of the equations used to calculate canopy indices were originally developed using passive light sources, aerial or satellite platforms, and for measuring a variety of canopy types (crop, grassland, or forest canopies). This may be part of the reason why those canopy indices were not well calibrated to corn $\mathrm{N}$ response. The rNDVI, rSRI, modified simple ratio index (rMSRI), and $\mathrm{rCHL}$ relative indices were best calibrated, with the quadratic-plateau regression models for the rNDVI, rSRI, and rCHL given in Table 2. The rMSRI relative index calibration model was quite similar to the rSRI and rCHL, and therefore not shown.

The GS-506 and GS-505 sensors had greater variation in the relationship between canopy indices and dEONR compared to the CC-210 sensor (Table 2). It is not know why that occurred. The difference in active sensor performance could be due to the different light source wavelengths (VIS $590 \mathrm{~nm}$ vs. VIS $560 \mathrm{~nm}$ and NIR $880 \mathrm{~nm}$ vs. NIR $774 \mathrm{~nm}$ ), average field of view, or light detection electronics. The GS-506 sensor is not a commercially available product.

Table 2 and Fig. 1 show the relative canopy index calibration models and equation parameters for the active sensors. Each of the relative canopy indices have a similar value at zero dEONR (0.99 - 1.00). The join point values were similar for the rSRI and rCHL (39 to $57 \mathrm{lb} \mathrm{N} /$ acre), but lower for the rNDVI index (-13 to $27 \mathrm{lb}$ N/acre). In some of the active canopy sensor indices, there were site-year responses that exhibited greater relative index values than the regression model plateau of 1.00 or 1.01 (Fig. 1). This occurred near zero dEONR, and was minimized with the CC-210 rNDVI index. The relative canopy index value rate of change per $\mathrm{lb}$ N/acre (model slope) was greatest with the rCHL and rSRI and the least with rNDVI. The larger model slope 
reflects the greater range of relative index values across dEONR. That is, indices relating to canopy biomass (rNDVI) had a reduced range of relative values across deficit dEONR than indices relating to canopy chlorophyll (rCHL, rSRI, and rMSRI). This may be due to the more subtle differences in canopy biomass across varying level of $\mathrm{N}$ compared to canopy chlorophyll.

With several indices having similar calibration goodness of fit, choice of a model to use as an $\mathrm{N}$ rate algorithm could be flexible, with focus more on canopy biomass (rNDVI) or canopy chlorophyll (rCHL, rSRI, or rMSRI). Across sensors the rCHL and rSRI indices (Figs. 1 and 2) have the same calibration model and $\mathrm{N}$ application rate relationship. Since the index calculation is computationally similar for CHL and SRI, it makes sense that the calibrations are the same for both indices. For rNDVI, the GS-505 and CC-210 have the same relationship to dEONR, but the GS-506 is different. Since the GS-505 was used only in 2007, these relationships were evaluated with all sensors for data just from that year (data not shown). That comparison between canopy indices was the same as with the three-year data.

\section{Prescribed N Rate and Variation}

Solving the quadratic portion of the quadratic-plateau calibration model produces an algorithm that can be used to prescribe $\mathrm{N}$ application rates. The graph of these algorithm results are shown in Fig. 2 for each sensor and the rCHL, rSRI, and rNDVI relative canopy indices. As the relative index values increase, the $\mathrm{N}$ rate prescription decreases and rapidly approaches zero as the relative index nears 1.0. This accelerated decrease in $\mathrm{N}$ rate per unit of relative index value, along with the variation in canopy index measurements, results in greater potential for $\mathrm{N}$ rate error at slight $\mathrm{N}$ deficiency. An important outcome of the calibration and $\mathrm{N}$ rate algorithm development is the need to have a calibration and $\mathrm{N}$ rate prescription algorithm specific for the active sensor and index combination. One calibration $/ \mathrm{N}$ rate prescription may not work appropriately for different sensors or indices.

Figure 3 shows the prescribed $\mathrm{N}$ rate variability across deficit dEONR for the GS-506 and CC210. With only one year of data, the GS-505 was not included in Fig. 3. In general, the sensor indices had similar change in prescribed $\mathrm{N}$ variability across deficit dEONR. However, the CC210 rNDVI generally had the lowest prescribed $\mathrm{N}$ rate variability. Variability in rate was least at -50 to $-150 \mathrm{lb} \mathrm{N} /$ acre dEONR, with greater uncertainty at 0 to -50 and $<-150 \mathrm{lb} \mathrm{N} /$ acre dEONR.

If active canopy sensors are to be used for determining needed in-season $\mathrm{N}$ application rates, then assessing the level of accuracy for prediction models is needed. Our results indicate that based on the $95 \%$ confidence limits for the calibration models, sensing slight $\mathrm{N}$ deficiencies (algorithm prescribed in-season $\mathrm{N}$ application between 0 to $50 \mathrm{lb} \mathrm{N} /$ acre) produce greater variability in prescribed $\mathrm{N}$ rate and therefore would reduce the effectiveness of using active sensor based $\mathrm{N}$ stress detection for incremental or fine-tuning $\mathrm{N}$ application. There may be several reasons for this, including a reduced slope in all index models as dEONR approaches zero $\mathrm{lb} \mathrm{N} /$ acre (adequate to excess $\mathrm{N}$ ) and site-year variability $\left(\operatorname{adj} R^{2}\right.$ for all regression models $\leq$ 0.75 ) in the relationship between deficit $\mathrm{N}$ and relative sensor index values. This is similar to issues in sensitivity with $\mathrm{N}$ stress sensing using the SPAD meter (Hawkins et al., 2007). Also, when corn is only slightly $\mathrm{N}$ deficient, the leaf area index of the canopy is near its greatest level and varies only somewhat from that with adequate N. This may explain why the CC-210 rNDVI demonstrated the lowest prescribed $\mathrm{N}$ rate variability in this study. Within certain limitations, 
such as associated with detecting slight $\mathrm{N}$ deficiencies, sensing with active sensors can address spatial $\mathrm{N}$ variability and has potential to improve field scale $\mathrm{N}$ management when compared with other $\mathrm{N}$ management strategies.

\section{Summary}

Active canopy sensors can measure $\mathrm{N}$ stress during the mid-vegetative corn growth period. When sensing was performed at the V10 - V12 growth stages, calibration models related relative sensor indices to corn $\mathrm{N}$ adequacy/deficit across diverse growing conditions (adj $R^{2}$ up to 0.75 for the calibration models). The active sensors and associated canopy indices presented unique combinations of $\mathrm{N}$ stress sensing capability. Canopy indices from the GS-506, GS-505, and CC210 sensors varied in the ability to differentiate corn $\mathrm{N}$ stress, that is, the range in relative index values across deficit $\mathrm{N}$, and varied in the calibration fit to $\mathrm{N}$ rate response. The GS-506 and GS505 sensor indices had lower adj $\mathrm{R}^{2}$ compared to the CC-210 sensor. Also, the rNDVI produced a narrower range in relative values from most to least $\mathrm{N}$ deficit than the rSRI and rCHL and smaller absolute variation at a given dEONR. Several relative canopy indices could be used to determine in-season $\mathrm{N}$ rate need. For these sensors, the rNDVI, rSRI, rMSRI, and rCHL are options for use in prescribing $\mathrm{N}$ applications. Choice could be made on the desire for more information relative to canopy biomass or canopy chlorophyll, and range in relative index values with $\mathrm{N}$ deficit corn.

The quadratic solution of the index calibration models developed in this study provide $\mathrm{N}$ rate algorithms capable of directing variable in-season $\mathrm{N}$ rate application in Iowa and other similar corn production areas. Nitrogen application would be directed when the relative index value is less than the value at zero dEONR. Care is needed to differentiate low index readings that are due to factors affecting plant growth and biomass other than $\mathrm{N}$ deficiency (examples are low plant population, plant damage from excess water, or other nutrient deficiencies) that would incorrectly indicate $\mathrm{N}$ fertilization need when perhaps none should be applied. In addition is the uncertainty in differentiating $\mathrm{N}$ stress and variability in sensor rate prediction between slight $\mathrm{N}$ deficiency and adequate/excess $\mathrm{N}$. Therefore, it would be helpful if additional parameters could be incorporated into variable $\mathrm{N}$ rate prescriptions to help minimize misapplication.

\section{Acknowledgements}

Appreciation is extended to the Iowa State University research farm superintendents and their staff for efforts with the research trials, including $\mathrm{N}$ applications and crop harvest. This research was supported in part by the Iowa State University Corn-Soybean Initiative and the Iowa Department of Agriculture and Land Stewardship, Division of Soil Conservation through funds

appropriated by the Iowa General Assembly for the Integrated Farm and Livestock Management Demonstration Program.

\section{References}

Dellinger, A.E., J.P. Schmidt, and D.B. Beegle. 2008. Developing nitrogen fertilizer recommendations for corn using an active sensor. Agron. J. 100:1546-1552. 
Hawkins, J.A., J.E. Sawyer, D.W. Barker, and J.P. Lundvall. 2007. Using relative chlorophyll meter values to determine nitrogen application rates for corn. Agron. J. 99:1034-1040.

Raun, W.R., J.B. Solie, G.V. Johnson, M.L. Stone, R.W. Mullen, K.W. Freeman, W.E. Thomason, and E.V. Lukina. 2002. Improving nitrogen use efficiency in cereal grain production with optical sensing and variable rate application. Agron. J. 94:815-820.

Schmidt, J.P., A.E. Dellinger, and D.B. Beegle. 2009. Nitrogen recommendations for corn: an on-the-go sensor compared with current recommendations. Agron. J. 101:916-924.

Sripada, R.P., J.P. Schmidt, A.E. Dellinger, and D.B. Beegle. 2008. Evaluating multiple indices from a canopy reflectance sensor to estimate corn N requirements. Agron. J. 100:1553-1561.

Solari, F., J. Shanahan, R. Ferguson, J. Schepers, and A. Gitelson. 2008. Active sensor reflectance measurements of corn nitrogen status and yield potential. Agron. J. 100:571-579.

Solari, F., J.F. Shanahan, R.B. Ferguson, and V.I. Adamchuk. 2010. An active sensor algorithm for corn nitrogen recommendations based on a chlorophyll meter algorithm. Agron. J. 102:1090-1098.

Teal, R.K., B. Tubana, K. Girma, K.W. Freeman, D.B. Arnall, O. Walsh, and W.R. Raun. 2006. In-season prediction of corn grain yield potential using normalized difference vegetation index. Agron. J. 98:1488-1494.

Zillmann, E., S. Graeff, J. Link, W.D. Batchelor, and W. Claupein. 2006. Assessment of cereal nitrogen requirements derived by optical on-the-go sensors on heterogeneous soils. Agron. J. 98:682-690. 
Table 1. Equations used to calculate canopy indices for the GreenSeeker 505 (GS-505), GreenSeeker 506 (GS506), and Crop Circle ACS-210 (CC-210) active sensors.

\begin{tabular}{|c|c|}
\hline Canopy index ${ }^{\dagger}$ & Equation \\
\hline & GS-505 and GS-506 \\
\hline NDVI & Index directly from the sensors \\
\hline SRI & Index directly from the sensors \\
\hline MSRI & $\mathrm{CHL} /(\mathrm{SRI})^{0.5}+1$ \\
\hline \multirow[t]{2}{*}{ CHL } & $\mathrm{SRI}-1$ \\
\hline & CC-210 \\
\hline NDVI & $(\mathrm{NIR}-\mathrm{VIS}) /(\mathrm{NIR}+\mathrm{VIS})$ \\
\hline SRI & NIR / VIS \\
\hline MSRI & $(\mathrm{NIR} / \mathrm{VIS})-1 /(\mathrm{NIR} / \mathrm{VIS})^{0.5}+1$ \\
\hline CHL & $(\mathrm{NIR} / \mathrm{VIS})-1$ \\
\hline NLI & $\left(\mathrm{NIR}^{2}-\mathrm{VIS}\right) /\left(\mathrm{NIR}^{2}+\mathrm{VIS}\right)$ \\
\hline MNDVI & $\left(\mathrm{NIR}^{2}-\mathrm{VIS}\right) /\left(\mathrm{NIR}+\mathrm{VIS}^{2}\right)$ \\
\hline RDVI & $(\mathrm{NIR}-\mathrm{VIS}) /(\mathrm{NIR}+\mathrm{VIS})^{0.5}$ \\
\hline NIR & NIR \\
\hline VIS & VIS \\
\hline \multicolumn{2}{|c|}{$\begin{array}{l}\dagger \text { NDVI, normalized difference vegetative index; SRI, } \\
\text { simple ratio index, MSRI, modified simple ratio index; } \\
\text { CHL, chlorophyll index; NLI, non-linear index; MNDVI, } \\
\text { modified normalized difference vegetative index; RDVI, } \\
\text { re-normalized difference vegetative index; NIR, near- } \\
\text { infrared reflectance; VIS, visible reflectance. }\end{array}$} \\
\hline
\end{tabular}


Table 2. Quadratic-plateau regression models and parameters for the relative canopy indices derived from the GreenSeeker 505 (GS-505), GreenSeeker 506 (GS-506), and Crop Circle ACS-210 (CC-210) active sensors.

\begin{tabular}{|c|c|c|c|c|c|c|}
\hline \multirow[b]{2}{*}{$\begin{array}{l}\text { Canopy } \\
\text { index }^{\dagger}\end{array}$} & \multirow[b]{2}{*}{ Regression model ${ }^{\star}$} & \multirow[b]{2}{*}{$\mathrm{n}$} & \multirow[b]{2}{*}{$\begin{array}{c}\text { Join } \\
\text { point }^{\S}\end{array}$} & \multicolumn{2}{|c|}{ Canopy index@ } & \multirow[b]{2}{*}{$\operatorname{Adj} R^{2 \pi}$} \\
\hline & & & & Plateau & $\begin{array}{c}\text { Zero } \\
\text { dEONR }\end{array}$ & \\
\hline & \multicolumn{6}{|c|}{ lb N/acre } \\
\hline & \multicolumn{6}{|c|}{$\underline{\text { GS-505 }}$} \\
\hline rNDVI & $y=1.00-0.000100 x-0.0000040 x^{2}$ & 129 & -13 & 1.00 & 1.00 & 0.68 \\
\hline rSRI & $y=0.99+0.000438 x-0.0000063 x^{2}$ & 129 & 35 & 1.00 & 0.99 & 0.60 \\
\hline $\mathrm{rCHL}$ & $y=0.99+0.000476 x-0.0000073 x^{2}$ & 129 & 33 & 1.00 & 0.99 & 0.60 \\
\hline & \multicolumn{6}{|c|}{ GS-506 } \\
\hline rNDVI & $y=1.00+0.000200 x-0.0000037 x^{2}$ & 367 & 27 & 1.00 & 1.00 & 0.56 \\
\hline rSRI & $y=0.99+0.000553 x-0.0000049 x^{2}$ & 367 & 56 & 1.00 & 0.99 & 0.65 \\
\hline $\mathrm{rCHL}$ & $y=0.99+0.000690 x-0.0000061 x^{2}$ & 367 & 57 & 1.01 & 0.99 & 0.64 \\
\hline & \multicolumn{6}{|c|}{$\mathrm{CC}-210$} \\
\hline rNDVI & $y=1.00+0.000072 x-0.0000032 x^{2}$ & 394 & 11 & 1.00 & 1.00 & 0.75 \\
\hline rSRI & $y=1.00+0.000403 x-0.0000052 x^{2}$ & 394 & 39 & 1.00 & 1.00 & 0.75 \\
\hline $\mathrm{rCHL}$ & $y=1.00+0.000486 x-0.0000063 x^{2}$ & 394 & 39 & 1.00 & 1.00 & 0.74 \\
\hline
\end{tabular}
chlorophyll index.

$\$$ For regression model, $y$ is the relative canopy index value; $x$ is the $\mathrm{N}$ rate differential from the EONR (dEONR), lb N/acre. The models for the GS-505 are from data collected in 2007 only. All models significant at the $P<0.001$.

$\S$ Nitrogen rate where the quadratic equation joins the canopy index plateau value.

ๆ Adjusted $R^{2}$. 

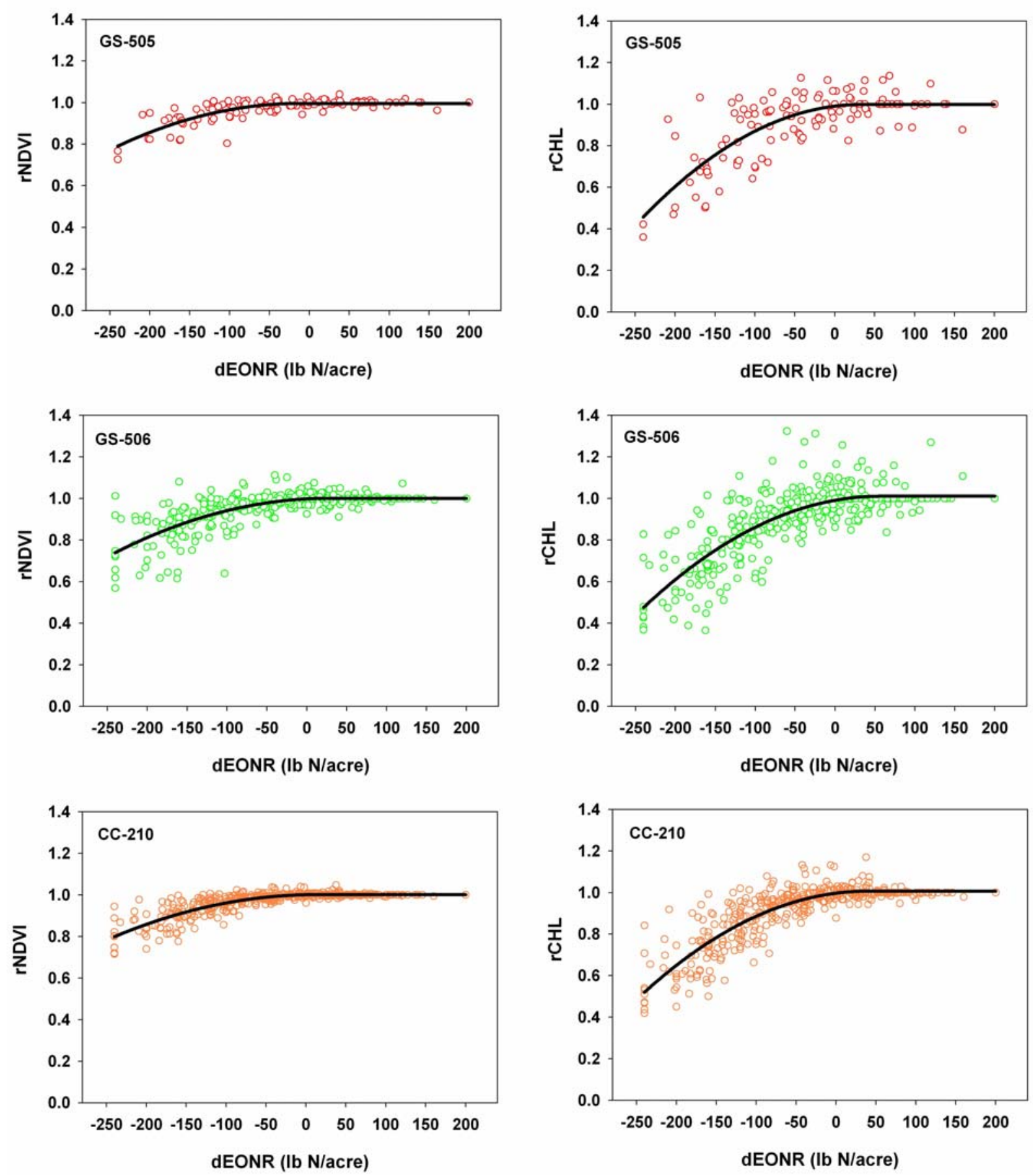

Fig. 1. Relative canopy index values and regression models as related to the differential from the economic optimum N rate (dEONR) for the GreenSeeker 505 (GS-505), GreenSeeker 506 (GS-506), and Crop Circle ACS-210 (CC-210) active sensors. 

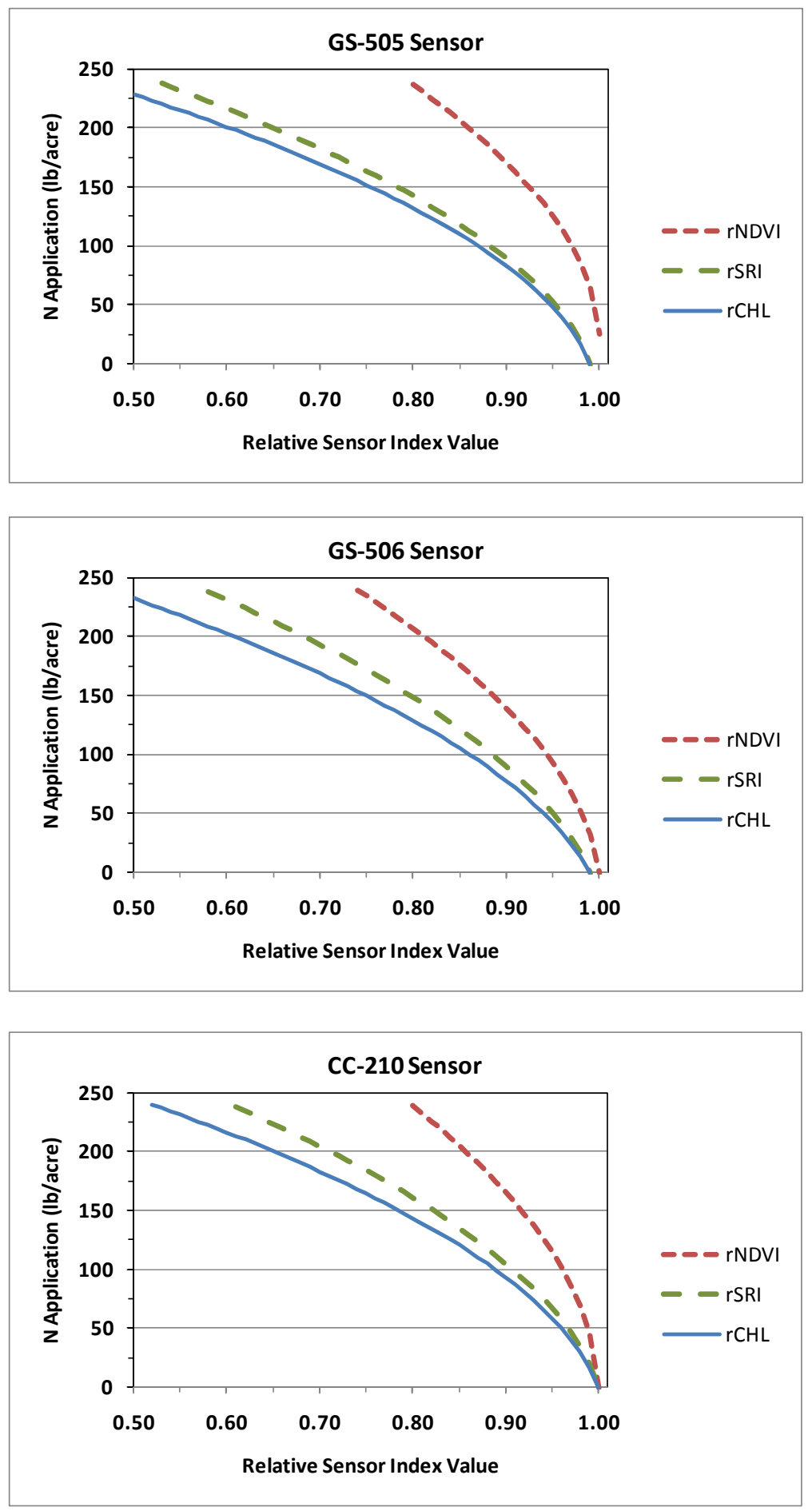

Fig. 2. Nitrogen rate application prescriptions derived from the calibration models for the relative canopy indices from the GreenSeeker 505 (GS-505), GreenSeeker 506 (GS-506), and Crop Circle ACS-210 (CC-210) active sensors. 


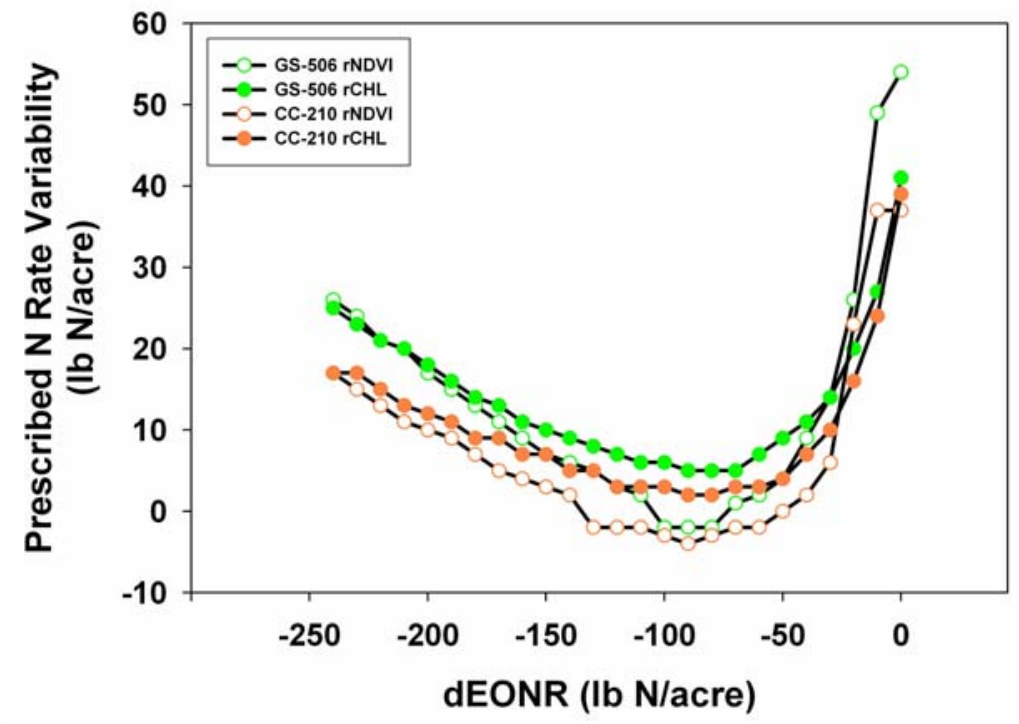

Fig. 3. Sensor prescribed $\mathrm{N}$ rate variability across deficit differential economic optimum $\mathrm{N}$ rates (dEONR) for relative canopy indices from the GreenSeeker 506 (GS-506) and Crop Circle ACS-210 (CC-210) active sensors. 